\title{
Frequency of myotonic dystrophy gene carriers in cataract patients
}

A M Cobo, J J Poza, A Blanco, A López de Munain, A Saénz, M Azpitarte, J Marchessi, J F Martí Massó

\begin{abstract}
DNA samples from 231 unselected patients with cataracts were studied to determine the frequency of the DM mutation in cataract patients. A previous epidemiological study established a high prevalence of DM in the population of Guipúzcoa (Basque Country, Spain), 26.5 cases $/ 100$ 000. We have found two carriers $(0.9 \%)$ of the DM mutation in patients who are not related to any previously known DM family. The screening of the DM mutation in cataract patients should be restricted to young patients or people with multicoloured and iridescent opacities, in which the risk of carrying the $D M$ premutation could be higher. Our results suggest that subjects with 38 to 80 repeats could constitute the genetic reservoir of the DM mutation. ( $f$ Med Genet 1996;33:221-223)
\end{abstract}

Key words: myotonic dystrophy gene; cataracts.

In the absence of any evident clinical features, identification of typical subcapsular opacities in subjects at risk of myotonic dystrophy (DM) was used as an indicator of a minimally affected gene carrier before the characterisation of the DM mutation. The identification of a specific mutation involving an unstable CTG repeat sequence in DM patients ${ }^{1-3}$ has provided an accurate molecular test for the disorder, and has allowed the detection of minimally affected subjects with a premutation (50 to $100 \mathrm{CTG}$ repeats). ${ }^{4} \mathrm{DM}$ premutation carriers with cataracts and no family history of DM could constitute the genetic reservoir of the DM mutation in the population. In a recent and extensive epidemiological study, in which we have tested nearly all the members of the families with the disease, we have found a prevalence of 26.5 cases per 100000 in Guipúzcoa, a province of the Spanish Basque Country. ${ }^{5}$ This is the second highest prevalence reported after the one found in the Saguenay-Lac-St-Jean region (189/100 000) in Québec, Canada. ${ }^{6}$ The assessment of the DM premutation in an unselected sample of cataract patients from a regional Ophthalmology Service could help to determine the genetic reservoir of the DM mutation in this high prevalence area.

\section{Materials and methods PATIENTS}

DNA was obtained from blood samples taken from 231 patients recruited prospectively, ranging in age from 21 to 91 years (mean age 72

\begin{tabular}{|c|c|c|c|c|c|}
\hline & \multicolumn{4}{|l|}{ Age } & \multirow[t]{2}{*}{ Tota } \\
\hline & $<45$ & $45-60$ & $61-75$ & $>75$ & \\
\hline Men & 2 & 13 & 54 & 32 & 102 \\
\hline Women & 4 & 7 & 54 & 63 & 129 \\
\hline Total & 6 & 20 & 108 & 95 & 231 \\
\hline
\end{tabular}

years), and presenting at the eye clinic of the Ntra Sra de Aránzazu Hospital. Patients with evident signs of DM or related to previously known DM families were excluded. The presence of other risk factors for developing cataracts, such as arterial hypertension or diabetes, was assessed in all patients. The age at the time of cataract surgery and sex distribution are shown in the table. The patients were informed about the possible genetic cause of their cataract and the purposes of this study, which was approved by the ethics committee of our hospital. The patients with a positive result were informed by a neurologist (ALM) and genetic counselling was offered.

\section{PCR ANALYSIS}

PCR analysis of the CTG repeats in the DM gene was performed as described previously ${ }^{4}$ with the following minor modifications. Reactions were performed in a $30 \mu \mathrm{l}$ volume containing $1 \mu \mathrm{mol} / 1$ of each primer, $1 \times \mathrm{PCR}$ buffer $(50 \mathrm{mmol} / 1 \mathrm{KCl}, 10 \mathrm{mmol} / 1$ Tris $\mathrm{HCl}, \mathrm{pH} 8 \cdot 3$, $0.01 \%$ gelatine, $1.5 \mathrm{mmol} / 1 \mathrm{MgCl}_{2}$ ), $200 \mu \mathrm{mol} / 1$ each of dATP, dCTP, dGTP, and dTTP, 700 ng DNA, and 1 U Taq polymerase. Cycling parameters were as follows: $94^{\circ} \mathrm{C}$ for three minutes, 30 cycles of $94^{\circ} \mathrm{C}$ for one minute 30 seconds, $67^{\circ} \mathrm{C}$ for one minute, $72^{\circ} \mathrm{C}$ for two minutes. Final extension was at $72^{\circ} \mathrm{C}$ for seven minutes. PCR products and the marker pBR322 digested with MspI (New England Biolabs) were run for two hours on 3\% Metaphor agarose (FMC) gels at $200 \mathrm{~mA}$ and visualised with ethidium bromide. This protocol can detect from five $(128 \mathrm{bp})$ to up to 130 to 140 (560 bp) CTG repeats (fig 1).

\section{STATISTICAL ANALYSIS}

Statistics were performed using SYSTAT package (PC version $5 \cdot 0)$. ANOVA test and Pearson correlation matrix were used when appropriate.

\section{Results}

As seen in fig $1 \mathrm{~A}$, the modified PCR protocol is very efficient for detecting clearly up to 140 


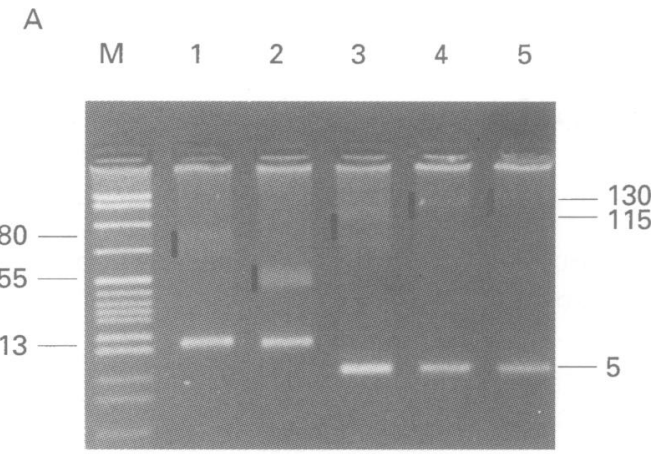

B

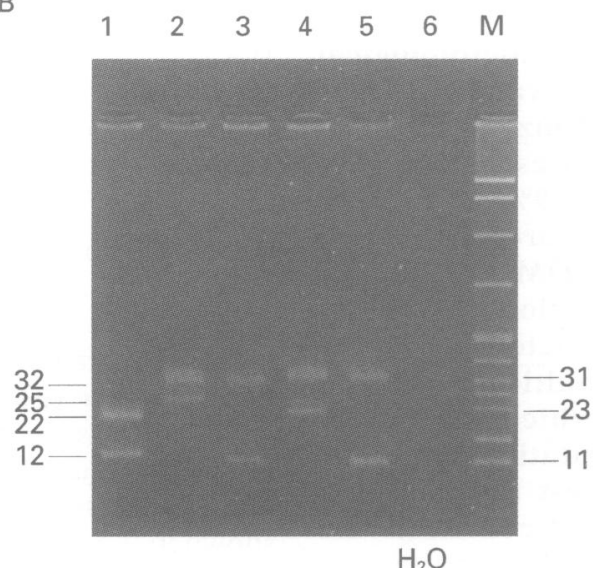

Figure 1(A) The small expansions which can be detected with our modified PCR protocol. The expanded bands appear fuzzy although they can be clearly detected up to $140 C T G$ repeats. M represents the pBR322 marker digested with MspI and gives the following bands from the top to the bottom of the gel: $622 \mathrm{bp}, 527 \mathrm{bp} \mathrm{(138CTG}$ repeats), $404 b p$ (97 CTG repeats), $307 b p$ (65 CTG repeats), $242 b p$ (43 CTG repeats), $238 b p$ (41 CTG repeats), $217 \mathrm{bp}$ (35 CTG repeats), $201 \mathrm{bp}$ (30 CTG repeats), $190 \mathrm{bp}$ (26 CTG repeats), $180 \mathrm{bp}$ (23 CTG repeats), $160 \mathrm{bp}$ (16 CTG repeats), $147 \mathrm{bp}$ (11 CTG repeats), and $123 \mathrm{bp}$ (5CTG repeats). 1 is the 74 year old cataract patient with 80 repeats and 2 is the 47 year old patient with 55 repeats. 3-5 are minimally affected DM patients as DM positive controls with 115 and 130 repeats. (B) High resolution of the 3\% metaphor agarose gel for the sizing of the normal repeats in selected cataract patients. (1) Patient with 12 and 22 repeats. (2) Patient with 25 and 31 repeats. (3) Patient with 11 and 31 repeats. (4) Patient with 23 and 32 repeats. (5) Patient with 11 and 31 repeats. (6) No DNA, negative control. $M: p B R 322 / M s p I$ digest.

CTG repeat expansions. The patients with minimal signs of DM (cataracts or myotonic discharges on EMG or both) have expansions in this range.$^{7-9}$ Patients with larger expansions, except children and young people, present other clinical signs suggestive of DM, which constitute exclusion criteria for our study. Fig $1 \mathrm{~B}$ shows an example of normal repeats in cataract patients. The marker used as a repeat number standard and the resolution obtained allow alleles of 31 and 32 repeats to be distinguished.

In our series, we have observed the same trimodal allele distribution in the normal size range ( 5 to 37 CTG repeats) as the one previously reported for white populations (fig 2 ). ${ }^{10}$ No relationship was found between the number of CTG repeats and sex (ANOVA $p=0.64$ ), age (Pearson correlation matrix -0.08 ), pres-

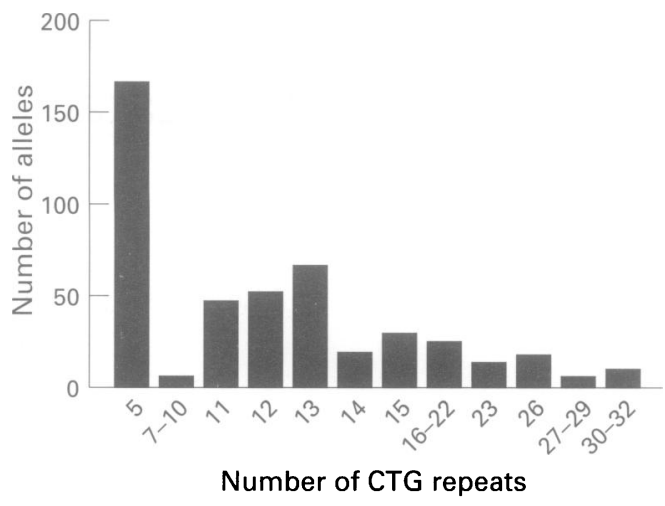

Figure 2 Frequency distribution of the CTG repeat in cataract patients.

ence of diabetes (ANOVA $\mathrm{p}=0 \cdot 71$ ), or arterial hypertension (ANOVA $\mathrm{p}=0.94$ ).

Two DM premutation carriers were found. One of them was a 74 year old man with diabetes and arterial hypertension, who had an expansion of 80 CTG repeats, and the other was a 47 year old woman with an expansion of 55 CTG repeats. Both of them came from the Bajo-Deba area of Guipúzcoa where the prevalence of the disease is the highest (30.9/ $100000) .^{5}$

\section{Discussion}

Until now, only two studies have analysed the risk to cataract patients of being DM carriers. ${ }^{112}$ Harley et al ${ }^{11}$ found no DM carriers among 101 cataract patients. ${ }^{11}$ Kidd et al ${ }^{12}$ found six patients with the DM mutation out of 113 patients studied ( 17 were analysed retrospectively). However, their inclusion criteria were not as strict as ours, since three had signs, symptoms, and even an evident familial history of DM, whereas in our study these patients were excluded. Considering only the other three patients, the prevalence of DM among cataract patients found by Kidd $e t a l^{12}$ is higher than ours. This could be because of the age difference in both series; the patients younger than 60 (inclusion criteria in the study of Kidd et $a l^{12}$ constitute only $11 \%$ of our sample. We have observed that $0.9 \%$ of our cataract patients carry the DM premutation. The percentage obtained is very low to recommend genetic screening for the DM mutation in all the cataract patients. However, we must consider the importance of the detection of DM premutation carriers, owing to the anticipation phenomenon. These subjects are at risk of having children with typical DM and grandchildren with congenital DM, especially when the DM premutation is transmitted by a male. ${ }^{13}$ The detection of DM premutation carriers could help to prevent the occurrence of congenital cases in families without a clinical history of typical DM. Screening for the DM mutation in cataract patients should be restricted to young patients or subjects with multicoloured and iridescent opacities, in whom the risk of carrying the DM premutation could be higher. It is interesting to note that in our study, a frequency of the DM mutation of 
$1 / 26$ in the age group less than 60 years was found, whereas in those over 60 years, the proportion was only $1 / 203$.

It has been postulated that "trinucleotide diseases" like myotonic dystrophy could be time bombs within the human genome. ${ }^{14}$ The strong tendency towards expansion of repeats, shown by Rubinsztein et $a l^{15}$ in Huntington disease, ${ }^{15}$ would lead to a steady increase over time in the frequency of alleles in the premutation range coming from alleles at the highest end of the normal range. However, in our cataract patients, we have not found subjects in the 33 to 50 repeat range, which could be ready to pass the threshold in few generations. Moreover, we have not found intergenerational variation in the transmission of normal CTG repeats (5 to 37 ) in 346 parent-child pairs, of which 62 were transmissions of alleles in the 19 to 33 repeat range. ${ }^{16}$ Unfortunately we were not able to study the parents (dead) who transmitted the DM mutation to our two cataract patients. The 47 year old woman with 55 repeats had no first degree relatives and the offspring of the other patient declined to participate in the study. Even if the patients had not had a direct relationship with any known DM family, we suspect they could belong to asymptomatic unknown collateral branches of symptomatic DM families which were not included in our epidemiological study. ${ }^{5}$ In the first case, the patient was from a small village with a high prevalence of DM and the other patient shared the same rare family name as a known DM family from a neighbouring province.

The genetic reservoir of the disease could be the generally mildly affected patients (with cataracts as the only sign of the disease) in the 38 to 80 (CTG) $)_{n}$ range, derived from collateral branches of DM pedigrees. Some premutated alleles between 38 and 80 repeats can expand from 120 and up to 1000 repeats in some cases especially in male transmissions, ${ }^{17-19}$ while in other cases, the premutated alleles are transmitted silently over generations. ${ }^{19}$ The alleles which expand would replace the losses owing to the reduction in fitness and marriage produced by the disease. ${ }^{20}$ For a better understanding of the dynamics of the DM mutation in this range, the next step should be the study of young cataract patients with the DM premutation, their parents, and, if possible, their grandparents, in order to look for the ancestral origin of the premutated allele and try to determine the moment where the jump to instability occurred.

This work was supported by a grant (94/1249) of "Fondo de Investigaciones Sanitarias" of the Spanish Ministry of Health.

1 Aslanidis C, Jansen G, Amemiya C, et al. Cloning of the essential myotonic dystrophy region and mapping of the defect. Nature 1992;355:548-51.

2 Buxton J, Shelbourne P, Davies J, et al. Detection of an unstable fragment of DNA specific to individuals with unstable fragment of DNA specific to individ
myotonic dystrophy. Nature 1992;355:547-8.

3 Harley HG, Brook JD, Rundle SA, et al. Expansion of an unstable DNA region and phenotypic variation in myotonic dystrophy. Nature 1992;355:545-7.

4 Brook JD, McCurrach ME, Harley HG, et al. Molecular basis of myotonic dystrophy: expansion of a trinucleotide (CTG) repeat at the $3^{\prime}$ end of a transcript encoding a protein kinase family member. Cell 1992;68:799-808

5 López de Munain A, Blanco A, Emparanza JI, et al. Prevalence of myotonic dystrophy in Guipuzcoa (Basque Country, Spain). Neurology 1993;43:1573-6.

6 Mathieu J, De Braekeler M, Prévost C. Genealogical reconstruction of myotonic dystrophy in the Saguenay-LacSaint-Jean area (Québec, Canada). Neurology 1990;40: Saint-Je

7 Melchionda S, Cobo A, Gennarelli M, et al. Expansion of the myotonic dystrophy gene in Italian and Spanish patients. $f$ Med Genet 1992;29:789-90.

8 Reardon W, Harley HG, Brook JD, et al. Minimal expression of myotonic dystrophy: a clinical and molecular analysis. f Med Genet 1992;29:770-3.

9 Harley HG, Rundle S, MacMillan JC, et al. Size of the unstable CTG repeat sequence in relation to phenotype and parental transmission in myotonic dystrophy. $A m \mathcal{F}$ Hum Genet 1993;52:1164-74.

10 Davies J, Yamagata H, Shelbourne P, et al. Comparison of the myotonic dystrophy associated CTG repeat in European and Japanese populations. F Med Genet 1992; 29:766-9.

11 Harley HG, Phillips M, Barnetson R, et al. Are cataract patients at high risk of being minimal DM gene carriers? Am $\mathcal{F}$ Hum Genet Suppl 1993;53:1730.

12 Kidd A, Turnpenny P, Kelly K, et al. Ascertainment of myotonic dystrophy through cataract by selective screening. F Med Genet 1995;32:519-23.

13 López de Munain A, Cobo AM, Poza JJ, et al. Influence of the sex of the transmitting grandparent in congenital myotonic dystrophy. $\mathcal{F}$ Med Genet 1995;32:689-91.

14 Mandel JL. Trinucleotide diseases on the rise. Nature Genet 1994;7:453-5.

15 Rubinsztein DC, Amos W, Leggo J, et al. Mutational bias provides a model for the evolution of Huntington's disease and predicts a general increase in diverse prevalence. Nature Genet 1994;7:525-30.

16 Cobo AM, Martorell L, Cornet M, et al. Threshold of instability of the expansion in the transmission of myotonic dystrophy. Neurologia (Barc) 1995;10:107.

17 Brunner HG, Brüggenwirth HT, Nillesen W, et al. Influence of the sex of the transmitting parent as well as of parental allele size on the CTG expansion in myotonic dystrophy. Am F Hum Genet 1993;53:1016-23.

18 Yamagata H, Miki T, Sakoda S, et al. Detection of a premutation in Japanese myotonic dystrophy. Hum Mol Genet 1994;3/5:819-20.

19 Barceló JM, Mahadevan M, Tsilfidis C, MacKenzie A, Korneluk R. Intergenerational stability of the myotonic dystrophy protomutation. Hum Mol Genet 1993;2:705-9.

20 Harper PS. Myotonic dystrophy. Philadelphia: WB Saunders, 1989. 